\title{
Knowledge, attitudes, and perceptions regarding child abuse and neglect among dentists in Turkey
}

\section{Burak BULDUR ${ }^{(a)}$ iD Çiğdem BÜYÜKKÖK(a) (ID}

Alessandro Leite CAVALCANTI(b)

(a) Sivas Cumhuriyet University, Faculty of Dentistry, Department of Pediatric Dentistry, Sivas, Turkey.

(b) Universidade Estadual da Paraíba - UEPB, Faculty of Dentistry, Department of Pediatric Dentistry, Campina Grande, PB. Brazil.

Declaration of Interests: The authors certify that they have no commercial or associative interest that represents a conflict of interest in connection with the manuscript.

\section{Corresponding Author:}

Burak Buldur

E-mail: bbuldur@gmail.com

https://doi.org/10.1590/1807-3107bor-2022.vol36.0001

Submitted: January 8, 2021

Accepted for publication: April 5, 2021

Last revision: May 17, 2021
Abstract: Limited research attention has been paid to Turkish dentists' perceptions of child abuse and neglect $(\mathrm{CA} / \mathrm{N})$. This study aimed to examine Turkish dentists' knowledge about, attitudes toward, and perceptions of CA/N. A total of 229 Turkish dentists responded to the self-administered, valid and reliable questionnaire. It consisted of 34 questions that could be classified into the following conceptual categories: a) sociodemographic data, b) knowledge about legal procedures and the orofacial characteristics and findings that are indicative of $\mathrm{CA} / \mathrm{N}$, and c) self-efficacy and attitudes toward CA/N. Multivariate analysis of variance was conducted and partial eta squared coefficients were used statistically. Knowledge about legal obligations was associated with occupational experience, highest CA/N education, frequency of child dental treatment. Prior experience with case of suspected CA/N demonstrated the greatest effects. Knowledge about the orofacial characteristics and findings that are indicative of $\mathrm{CA} / \mathrm{N}$ was associated with prior experience with at least one case of suspected $\mathrm{CA} / \mathrm{N}$. The most frequently provided reasons for failure to report cases of suspected $\mathrm{CA} / \mathrm{N}$ were fear that the child would be harmed. Turkish dentists demonstrated moderate levels of knowledge about their legal obligations and the orofacial characteristics and findings that are indicative of $\mathrm{CA} / \mathrm{N}$. Dentists should receive detailed education on $\mathrm{CA} / \mathrm{N}$ in their undergraduate and postgraduate education. In addition, it is necessary to increase awareness and knowledge about $\mathrm{CA} / \mathrm{N}$ by providing in-service trainings at the institutions where they work.

Keywords: Child Abuse; Dentists; Domestic Violence; Wounds and Injuries.

\section{Introduction}

Child abuse and neglect $(\mathrm{CA} / \mathrm{N})$ has emerged as an increasingly serious problem that has medical, legal, developmental, and psychosocial ramifications, complex causes, and tragic consequences. ${ }^{1,2}$ The World Health Organization (WHO) has defined child abuse as the intentional or unintentional behaviors of an adult that negatively affect a child's health and physical and psychosocial development. ${ }^{3} \mathrm{CA} / \mathrm{N}$ is classified into four types: neglect, and physical, sexual, and emotional abuse., ${ }^{4,5}$

Dentists occupy a strategic position that allows them to identify CA/N because a high proportion of orofacial injuries are sustained by $\mathrm{CA} / \mathrm{N}$ 
victims. ${ }^{6,7}$ Accordingly, these professionals can observe these injuries when they examine a patient physically and psychologically. ${ }^{8,9,10}$ Dentists must be adequately aware of $\mathrm{CA} / \mathrm{N}$ and should consider the possibility of $\mathrm{CA} / \mathrm{N}$ when they identify traumatic lesions in the oral cavity, teeth, and soft tissues during the intraoral examination of children, and the report made by the child is not compatible with the type of injury., ${ }^{411-14}$ When a sexually transmitted disease is detected in a child's oral cavity, the dentist should evaluate the case in terms of both child neglect and abuse. ${ }^{15,16}$ During these evaluations, it is imperative for dentists to possess knowledge about CA/N, know about the obligation to notify the authorities, and to ascertain possible CA/N. ${ }^{11}$ It is essential for physicians to be aware of their ethical, moral, and legal responsibilities with regard to $\mathrm{CA} / \mathrm{N}$ because they can inform authorities about their suspicions and take the necessary reparative measures to alleviate the grievances of the affected child..$^{17}$

Abuse is a globally subject that has been intensively studied, and it has been an increasing phenomenon throughout the world. There has been an increase in the research attention that has been paid to the awareness of $\mathrm{CA} / \mathrm{N}$ among dentists in many countries. ${ }^{8,17-23} \mathrm{~A}$ recent study that was conducted in collaboration with the United Nations Children's Fund (Unicef) in Turkey reported that 1186 Turkish children who were between the ages of 7 and 18 (girls: $54 \%$, boys: $46 \%$ ) had been exposed to emotional, physical, and sexual abuse with high incidence rates of $49 \%, 56 \%$, and $9 \%$, respectively. ${ }^{24}$ In Turkey, dentists are legally obligated to report suspicions about $\mathrm{CA} / \mathrm{N}$ to authorities. According to the Turkish Penalty Law, healthcare providers who do not report or delay their reporting of $\mathrm{CA} / \mathrm{N}$ cases to the authorities are punished with a severe penalty. Although there is a high incidence of CA/N in Turkey, ${ }^{25}$ limited research attention has been paid to the knowledge and attitudes of dentists toward CA/N and concomitant factors.

The present study aimed to examine Turkish dentists' knowledge, attitudes, and perceptions toward $\mathrm{CA} / \mathrm{N}$. Accordingly, three research questions were formulated: (a) how knowledgeable are dentists about their legal obligations and the orofacial characteristics and findings that are indicative of CA/N?; (b) which variables influence dentists' knowledge about their legal obligations and the orofacial characteristics and findings that are indicative of CA/N?; and (c) what is the level of self-efficacy that is demonstrated by dentists and how do they perceive the identification and reporting of $\mathrm{CA} / \mathrm{N}$ and additional education in this domain?

\section{Methodology}

\section{Study design and sample}

Ethical approval for this study was granted by the Health Ethics Committee of Author's University (ID: 2018-06/12). Further, written informed consent was also obtained from all the participants. This study adopted a national cross-sectional design and was conducted in a province (Turkey) between May 2018 and August 2018. A convenience sample of 229 practitioners and specialist dentists who belonged to different disciplines and was working in public hospitals, faculties of dentistry, and private clinics, was recruited. Dissenting and inaccessible dentists were not included in the study sample. Data were collected using questionnaires. One researcher from the study group (C.C.) went to each participant's workplace and waited with them as they filled out the forms. The average time that the participants took to complete the questionnaire was 8 minutes. The response rate was $100 \%$. For test-retest reliability, a randomly selected group of 50 participants filled out the questionnaire one month after the initial questionnaire was completed.

\section{Data collection}

A validated questionnaire was developed across several steps for the purpose of data collection. First, the conceptual framework and contents of the questionnaire were designed. A detailed literature search was conducted to identify published attitudes on similar subjects. Turkish and English databases were searched using the keywords "child abuse," "neglect," and "child abuse and neglect" to retrieve pertinent articles, guidelines, and books. Retrieved questionnaires that assessed pertinent constructs were reviewed. The resultant item pool of 45 questions was classified into the following categories as per 
the theoretical framework: (a) sociodemographic data, (b) knowledge about legal procedures and the orofacial characteristics and findings that are indicative of $\mathrm{CA} / \mathrm{N}$, and (c) self-efficacy, attitudes toward $\mathrm{CA} / \mathrm{N}$, and its status in dental education. With regard to content validity, the question pool was sent to an expert panel that consisted of three pediatric dentists, one psychologist, and a lawyer; these panelists did not participate in the main study or have any conflicts of interest that could interfere with the present study or findings. Based on the feedback that they had provided, 11 items were excluded from the item pool. Subsequently, a focus group interview was conducted with 10 dentists to assess the feasibility and validity of the questionnaire. Specifically, we examined whether the finalized questions were comprehensive and consistent with the conceptual framework of the assessment. Finally, the questionnaire was sent to a Turkish language expert who assessed its linguistic validity and drafted the final version of the questionnaire.

The questionnaire consisted of a total of 34 questions that could be classified into the following conceptual categories: a) sociodemographic data (6 questions), b) knowledge about legal procedures (5 questions) and the orofacial characteristics and findings that are indicative of CA/N (13 questions), and c) self-efficacy, attitudes toward $\mathrm{CA} / \mathrm{N}$, and its status in dental education (10 questions). Knowledge about legal obligations and the orofacial characteristics and findings that are indicative of $\mathrm{CA} / \mathrm{N}$ were assessed using multiple-choice questions. A score of 1 and 0 was assigned for each correct and incorrect answer, respectively. The composite scores could range from 0 to 18 . Higher scores are indicative of higher levels of knowledge. Total full scale scores were categorized as: 'no or little knowledge' (score range 1-4), 'low knowledge' (score range 5-9), 'moderate knowledge' (score range 10-14), and 'high knowledge' (score range 15-18). The questions regarding sociodemographic data and self-efficacy, attitudes toward CA/N, and its status in dental education modules were designed to be used not as scales but for epidemiological and educational purposes. Self-efficacy and attitudes toward CA/N and its status in dental education were assessed using multiple-choice or yes-no questions.

\section{Statistical analysis}

Statistical analyses were conducted using SPSS (Statistical Package for the Social Sciences) version 22.0. Descriptive statistics, namely, frequencies, means, and total scores were computed.

Internal reliability coefficients for the components specified in the questionnaire were calculated using Cronbach's $\alpha$ and intra-class correlation coefficient (ICC) values were used for test-retest reliability. For construct validity, the factor structure was examined using exploratory factor analysis (EFA) with rotated principal components analysis.

Multivariate analysis of variance was conducted and partial eta squared coefficients were computed to examine the effect of independent variables (i.e., gender, educational level, occupational experience, place of work, highest CA/N education, self-efficacy, frequency of child dental treatment, and prior experience with at least one case of suspected CA/N) on the dependent variables (i.e., legal obligations and orofacial characteristics and findings that are indicative of $\mathrm{CA} / \mathrm{N}$ ). Results with p-values that were $\leq 0.05$ were considered to be statistically significant.

\section{Results}

The study sample constituted of 124 men (54\%) and 105 women (46\%). The mean age of the participants was $32.49 \pm 7.41$ years. The mean score for knowledge about legal obligations and the orofacial characteristics and findings that are indicative of CA/N was 10.17 \pm 3.88 .

Kaiser-Meyer-Olkin coefficient (KMO) and Bartlett sphericity test were used to identify the compatibility of data for factor analysis. Data were found to be compatible for factor analysis since KMO value, 0.93 , and Barlett's sphericity test, $(\chi 2=6102.16, p<0.01)$, were statistically significant. Findings of EFA revealed a single factor, with an eigenvalue of 5.54 accounting for 81.724 of variance. The lower limit of the load value of items was 0.30 after varimax rotation, thus none of the items were excluded from the scale since load value of all items was greater than 0.30 .

Cronbach $\alpha$ internal reliability coefficient for the questionnaire was calculated as 0.90 . Corrected item-total correlations of the scale ranged from 0.74 to 0.91 , which shows the homogeneity of the 
questionnaire items. Test-retest reliability was found to be 0.84 .

Table 1 shows the mean scores for knowledge about legal obligations and the orofacial characteristics and findings that are indicative of $\mathrm{CA} / \mathrm{N}$ and their association with gender, education level, occupational experience, place of work, highest $\mathrm{CA} / \mathrm{N}$ education, self-efficacy, frequency of child dental treatment, and prior experience with at least one case of suspected $\mathrm{CA}$ N N Knowledge about legal obligations was associated with occupational experience, highest
$\mathrm{CA} / \mathrm{N}$ education, frequency of child dental treatment, and prior experience with at least one case of suspected $\mathrm{CA} / \mathrm{N}(\mathrm{p}<0.05)$. Among these variables, the frequency with which children were treated had the greatest effect on knowledge $\left(\mu^{2}=0.052\right)$. Participants' knowledge about legal obligations and the orofacial characteristics and findings that are indicative of $\mathrm{CA} / \mathrm{N}$ was associated with prior experience with at least one case of suspected CA/N $(\mathrm{p}<0.05)$. Associations among all other variables were not statistically significant $(p>0.05)$.

Table 1. Comparison of mean scores of knowledge about legal obligations and orofacial characteristics and findings that are indicative of child abuse and neglect $(\mathrm{CA} / \mathrm{N})$ by all participants and variables.

\begin{tabular}{|c|c|c|c|c|c|c|c|c|c|c|}
\hline \multirow{2}{*}{ Variables } & \multirow{2}{*}{$\mathrm{n}$} & \multirow{2}{*}{$\%$} & \multicolumn{4}{|c|}{ Orofacial findings } & \multicolumn{4}{|c|}{ Legal obligations } \\
\hline & & & Mean & \multicolumn{2}{|c|}{$95 \% \mathrm{Cl}$} & $\mathrm{p}$-value & Mean & \multicolumn{2}{|c|}{$95 \% \mathrm{Cl}$} & $\mathrm{p}$-value \\
\hline Women & 105 & 45.85 & 7.13 & 6.47 & 7.80 & & 2.73 & 2.47 & 3.00 & \\
\hline Men & 124 & 54.15 & 7.57 & 6.90 & 8.25 & & 2.87 & 2.66 & 3.09 & \\
\hline Education level & & & & & & $p>0.05$ & & & & $p>0.05$ \\
\hline Undergraduate & 139 & 60.70 & 7.08 & 6.52 & 7.64 & & 2.80 & 2.58 & 3.02 & \\
\hline Postgraduate & 90 & 39.30 & 7.80 & 6.98 & 8.66 & & 2.82 & 2.55 & 3.09 & \\
\hline Place of work & & & & & & $p>0.05$ & & & & $p>0.05$ \\
\hline Public & 99 & 43.23 & 7.06 & 6.39 & 7.73 & & 2.85 & 2.58 & 3.11 & \\
\hline University & 88 & 38.43 & 7.27 & 6.55 & 8.00 & & 2.78 & 2.53 & 3.03 & \\
\hline Private clinic & 34 & 14.85 & 8.31 & 6.90 & 9.72 & & 2.76 & 2.32 & 3.20 & \\
\hline \multicolumn{3}{|c|}{ Occupational experience (year) } & & & & $p<0.05 \mu^{2}=0.052$ & & & & $p>0.05$ \\
\hline $1-5$ & 82 & 35.81 & 7.21 & 6.46 & 7.96 & & 2.95 & 2.65 & 3.25 & \\
\hline $6-10$ & 59 & 25.76 & 7.10 & 6.21 & 7.99 & & 2.59 & 2.27 & 2.91 & \\
\hline $11-15$ & 69 & 30.13 & 7.04 & 6.08 & 8.01 & & 2.91 & 2.62 & 3.20 & \\
\hline$>16^{*}$ & 19 & 8.30 & 10.11 & 8.78 & 11.46 & & 2.47 & 1.80 & 3.14 & \\
\hline \multicolumn{3}{|c|}{ Highest $\mathrm{CA} / \mathrm{N}$ training } & & & & $p<0.05 \mu^{2}=0.043$ & & & & $p>0.05$ \\
\hline Undergraduate & 205 & 89.52 & 7.11 & 6.62 & 7.60 & & 2.75 & 2.58 & 2.92 & \\
\hline Postgraduate* & 24 & 10.48 & 9.58 & 8.08 & 11.09 & & 3.29 & 2.69 & 3.90 & \\
\hline \multicolumn{3}{|l|}{ Self-efficacy } & & & & $p>0.05$ & & & & $p>0.05$ \\
\hline Sufficient & 80 & 34.93 & 7.15 & 6.39 & 7.91 & & 2.95 & 2.65 & 3.25 & \\
\hline Neither nor & 57 & 24.89 & 7.04 & 6.16 & 7.92 & & 2.54 & 2.23 & 2.85 & \\
\hline Insufficient & 92 & 40.17 & 7.77 & 6.95 & 8.60 & & 2.85 & 2.58 & 3.11 & \\
\hline \multicolumn{6}{|c|}{ Frequency of child dental treatment (in a day) } & $p<0.05 \mu^{2}=0.054$ & & & & $p>0.05$ \\
\hline Never & 28 & 12.23 & 7.29 & 5.84 & 8.73 & & 2.96 & 2.40 & 3.50 & \\
\hline$<10$ & 97 & 42.36 & 7.20 & 6.56 & 7.90 & & 2.71 & 2.46 & 2.96 & \\
\hline $11-20$ & 72 & 31.44 & 6.71 & 5.89 & 7.53 & & 2.93 & 2.63 & 3.23 & \\
\hline$>20^{*}$ & 32 & 13.97 & 9.38 & 7.86 & 10.89 & & 2.69 & 2.20 & 3.18 & \\
\hline \multicolumn{6}{|c|}{ Suspect of $\mathrm{CA} / \mathrm{N}$ (at least one) } & $\mathrm{p}<0.05 \mu^{2}=.048$ & & & & $p<0.05 \mu^{2}=0.023$ \\
\hline Yes* & 50 & 21.83 & 8.88 & 7.76 & 9.98 & & 2.18 & 2.77 & 3.59 & \\
\hline No & 179 & 78.17 & 6.95 & 6.44 & 7.46 & & 3.70 & 2.52 & 2.88 & \\
\hline
\end{tabular}

*shows statistically significance; $\mathrm{Cl}$ : Confidence interval. 
Table 2 shows the distribution of correct answers that participants provided for each question that assessed their knowledge about legal obligations and the orofacial characteristics and findings that are indicative of $\mathrm{CA} / \mathrm{N}$. Figure presents the reasons that account for why the participants failed to inform authorities when they encountered cases of suspected CA/N. The most common reasons for not reporting cases of $\mathrm{CA} / \mathrm{N}$ were fears that the child will be harmed (30.4\%) and insufficient evidence to file a report (26.8\%). Additionally, most dentists had filed their reports of previously encountered cases of $\mathrm{CA} / \mathrm{N}$ in police stations (39.6\%).

Table 2. Distribution of correct answers by participants for each question for knowledge about legal procedures and the orofacial characteristics and findings that are indicative of child abuse and neglect.

\begin{tabular}{|c|c|c|c|}
\hline Questions & Correct answer & $\mathrm{n}$ & $\%$ \\
\hline \multicolumn{4}{|l|}{ Legal obligation } \\
\hline $\begin{array}{l}\text { The institution or clinic where you work has a protocol for recording and reporting suspicion of child abuse } \\
\text { and neglect }(C A / N) \text {. }\end{array}$ & Yes & 58 & 25.3 \\
\hline When dentists suspect child abuse and/or child neglect. Which of the following should they legally report? & $\begin{array}{l}\text { Both child abuse } \\
\text { and neglect }\end{array}$ & 42 & 18.3 \\
\hline What is the penalty if a dentist suspects $\mathrm{CA} / \mathrm{N}$ and does not report it? & Heavy panel & 54 & 23.6 \\
\hline $\begin{array}{l}\text { What is it considered when the caregiver fails to provide their child dental treatments, even though the } \\
\text { caregiver is aware of early childhood caries? }\end{array}$ & Child neglect & 52 & 22.7 \\
\hline Which institution must you report to if you suspect CA/N? & My supervisor & 30 & 13.1 \\
\hline \multicolumn{4}{|l|}{ Orofacial characteristics and findings } \\
\hline $\mathrm{CA} / \mathrm{N}$ is associated with low income. & Wrong & 99 & 43.2 \\
\hline Abused children often tell someone about the abuse. & Wrong & 125 & 54.6 \\
\hline If a child says that he or she has suffered harm from an adult, it should be taken seriously. & Right & 199 & 86.9 \\
\hline $\mathrm{CA} / \mathrm{N}$ should be suspected if a family delays medical treatment for a child's injury. & Right & 85 & 37.1 \\
\hline Children are not taken from their families in $\mathrm{CA} / \mathrm{N}$ cases. & Right & 103 & 45.0 \\
\hline Bruises on the cheek may be a sign of slapping or squeezing. & Right & 165 & 72.1 \\
\hline Bruises are usually seen in bony areas. & Right & 102 & 44.5 \\
\hline There is a strong relationship between dental neglect and physical neglect. & Right & 136 & 59.4 \\
\hline Colored or avulsed teeth may be a $\mathrm{CA} / \mathrm{N}$ finding due to repeated trauma. & Right & 178 & 77.7 \\
\hline Bruises around the neck are usually accidental. & Wrong & 166 & 72.5 \\
\hline Burns are usually associated with $\mathrm{CA} / \mathrm{N}$ and are generally similar to the shapes of items that get hot. & Right & 80 & 34.9 \\
\hline Bite marks in a routine dental examination are possible signs of $\mathrm{CA} / \mathrm{N}$. & Wrong & 176 & 76.9 \\
\hline Abnormal knowledge in children about sexual issues and maladaptive behaviors based on age are $C A / N$ findings. & Right & 189 & 82.5 \\
\hline
\end{tabular}

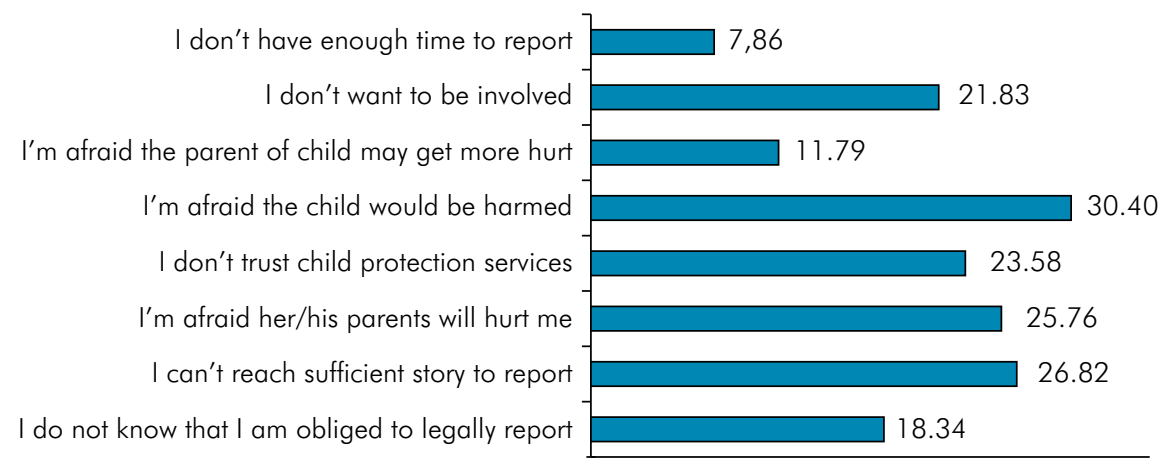

Figure. Reasons for not reporting when participants suspect child abuse and neglect (multiple choice was possible). 


\section{Discussion}

The incidence of CA/N has increased in Turkey. ${ }^{25,26}$ Further, victims of $\mathrm{CA} / \mathrm{N}$ often sustain injuries in the neck and orofacial areas. ${ }^{9}$ However, very limited research attention has been paid to Turkish dentists' knowledge about and attitudes toward CA/N. Thus, this study examined Turkish dentists' knowledge about and attitudes toward CA/N as well as the associations among variables that may influence their knowledge level. Overall, moderate levels of knowledge and insufficient dental education about $\mathrm{CA} / \mathrm{N}$ were observed among Turkish dentists.

This study has several limitations. First, the findings of this cross-sectional study used only a small and homogenous sample; therefore, the findings cannot be generalized to other groups. Second, other independent variables (e.g., cognitive and psychological status of the participants, anxiety, stress, trust) that can affect participants' perceptions were not investigated in this study. Another limitation is that the sample consisted of dentists who were working in a dental facility in a single city. In future studies, the samples must consist of a higher number of dentists who represent different cities and geographical regions. On the other hand, the strengths of this study include the development of a valid and reliable questionnaire that can be used as a psychometrically sound measurement tool. Further, the current study examined previously unexplored relationships between knowledge and awareness about $\mathrm{CA} / \mathrm{N}$ and several variables among Turkish dentists. The questionnaire developed for this study can be used in future studies as a valid and reliable measurement tool. In addition, this paper evaluated the effects of multiple variables on knowledge and attitudes regarding $\mathrm{CA} / \mathrm{N}$. Thus, the findings provide information beyond descriptive. However, knowledge about legal obligations and the orofacial characteristics and findings that is indicative of $\mathrm{CA} / \mathrm{N}$, both of which have implications for dentists who encounter cases of suspected CA/N, have been discussed in detail. In further studies, the effects of different independent variables on dentists' knowledge and perceptions on $\mathrm{CA} / \mathrm{N}$ should be examined in different societies and cultures. However, it is necessary to use cross-cultural adaptation procedures mentioned in the literature should be followed in order to adapt this questionnaire to different language.

The present findings reveal that participants possessed moderate levels of knowledge about their legal obligations, the signs and orofacial characteristics and findings that are indicative of $\mathrm{CA} / \mathrm{N}$, and concomitant issues. A higher figure (57\%) was reported in a previous study that was conducted in Tabriz..22 Despite possessing moderate levels of knowledge, $81.2 \%$ of the participants reported that they had not received training about $\mathrm{CA} / \mathrm{N}$ as a part of their undergraduate education. This ratio is consistent with those that have been previously reported for Greek ${ }^{23}$ and Danish dentists. ${ }^{8}$ Consistent with the present findings, Bodrumlu et al. ${ }^{27}$ observed that dental students in Turkey are not sufficiently trained to identify cases of suspected CA/N. This also concurs with the finding of another study that was conducted in the United Arab Emirates (UAE). ${ }^{28}$ Similarly, general dentists report uncertainty and low levels of self-efficacy with regard to their ability to recognize and report $\mathrm{CA} / \mathrm{N}$, which is attributable to their insufficient levels of knowledge. ${ }^{15,18,21,29}$ In this regard, a majority $(95.6 \%)$ of the participants, who considered themselves to be inadequately equipped to identify and report cases of suspected CA/N, expressed a need for additional training in this domain. Similarly, many past studies ${ }^{18} 2930$ have also found that dental professionals require additional education that equips them to identify, manage, and report cases of suspected $\mathrm{CA} / \mathrm{N}$.

In the present study, $21.8 \%$ of the respondents reported that they had encountered at least one case of suspected $\mathrm{CA} / \mathrm{N}$ during their professional career. This figure is similar to those that have been reported for different countries such Croatia $(26.2 \%){ }_{1}^{18}$ Scotland $(29 \%),{ }_{1}^{17}$, UAE (\%25), ${ }^{27}$ and Denmark (38.3\%). ${ }^{8}$ Despite the high rates of occupational experience of dentists, $147(64.2 \%)$ were 6 or more years of experience and $104(45.4 \%)$ dentists attended 11 or more children a day among the participants, the number of cases that are reported to legal authorities is low. The main barriers that prevented the respondents from reporting cases of suspected CA/N were "insufficient evidence (30.4\%) and fears that the child will be harmed by the 
ramifications of reporting $\mathrm{CA} / \mathrm{N}(26.8 \%)$. One possible reason for this is that anonymity for the dentists is not possible when reporting cases, so there may be concerns that the person who is notified would try to retaliate against them. These barriers were also most frequently reported by the Danish ${ }^{8}$ and Malaysian ${ }^{19}$ respondents. Different barriers have been identified in similar studies that have been conducted in different countries. ${ }^{15,17,18,28}$ In the present study, $21.8 \%$ of the respondents reported that they did not want to be involved. This may be due to several reasons, such as fear of inclusion in a lawsuit, distrust of the process for handling a suspect, and fear of a wrong diagnosis. In UAE, the fear of rendering an incorrect diagnosis of $\mathrm{CA} / \mathrm{N}$ was most frequently reported as the obstacle that impeded one from filing a report. ${ }^{28}$ On the other hand, in Saudi Arabia, a lack of knowledge about referral procedures and fear of anger from family members were the main causes of underreporting. ${ }^{28}$ Among Brazilian dentists, $50 \%$ of the responses that pertained to why the professionals did not report cases of physical violence against children were related to a fear of retaliation and difficulties in diagnosis. ${ }^{31}$ Among Croatian dentists, fear that a child may be subjected to violence and uncertainty about clinical observations were most frequently reported as the barriers that impeded the reporting of CA/N..$^{18}$ Further, only $11.4 \%$ of the participants possessed knowledge about the procedure that is involved in reporting CA/N. In the present study, $25.3 \%$ of the participants stated that they were unaware that their institution has a protocol based on which cases of suspected CA/N must be notified.

In the present study, $23.6 \%$ of the respondents possessed knowledge about legal ramifications of failure to report CA/N. Similarly, in another study, $16.7 \%$ of Malaysian dentists were found to be unaware that reporting $\mathrm{CA} / \mathrm{N}$ is a legal requirement in Malaysia; however, only $14.8 \%$ of them had reported such cases of suspected CA/N..$^{19}$ The reasons that underlie their failure to report these cases may be either personal in nature or attributable to the pertinent legal procedures in the country.

Turkish dentists were most likely to report cases of suspected $\mathrm{CA} / \mathrm{N}$ at local police stations, law enforcement institutions, and social service organizations. On the other hand, Croatian dentists were found to prefer discussing their cases of suspected $\mathrm{CA} / \mathrm{N}$ with their colleagues. In the present study, the second and third most preferred locations to report cases of suspected $\mathrm{CA} / \mathrm{N}$ were social service organizations and police stations, respectively. Since the participants believed that these cases were forensic in nature, they wanted to first file a report in a police station. However, they did not know that the supervisors of their institutions must be informed first. When there is suspicion of $\mathrm{CA} / \mathrm{N}$, it is necessary to establish a clear and standardized way regarding the kind of legal procedure dentists will follow. It would be useful if dentists received detailed education on $\mathrm{CA} / \mathrm{N}$ in their undergraduate and postgraduate education. In addition, it is necessary to increase awareness and knowledge about CA/N by providing in-service trainings at the institutions where they work. Dentists' awareness should also be raised that reporting CA/N suspicion is a legal obligation, rather than a personal preference.

\section{Conclusion}

Turkish dentists reported moderate levels of knowledge about their legal obligations and the orofacial characteristics and findings that are indicative of CA/N. They also reported that their undergraduate and postgraduate education had not adequately equipped them to handle cases of suspected $\mathrm{CA} / \mathrm{N}$. Courses on CA/N must be included as a part of undergraduate and postgraduate programs in dentistry. Institutions must formulate protocols that facilitate the diagnosis and management of $\mathrm{CA} / \mathrm{N}$.

\section{References}

1. Zeanah CH, Humphreys KL. Child abuse and neglect. J Am Acad Child Adolesc Psychiatry. 2018 Sep;57(9):637-44.

https://doi.org/10.1016/i.jaac.2018.06.007 
Knowledge, attitudes, and perceptions regarding child abuse and neglect among dentists in Turkey

2. Sano-Asahito T, Suzuki A, Matsuyama J, Mitomi T, Kinoshita-Kawano S, Hayashi-Sakai S, et al. Self-esteem and oral condition of institutionalized abused children in Japan. J Clin Pediatr Dent. 2015;39(4):322-5. https://doi.org/10.17796/1053-4628-39.4.322

3. Krug EG, Dahlber LL, Mercy Já, Zwi AB, Lozano R, editors. World report on violence and health. Genea: World Health Organization; 2002 Chapter 3: Child abuse and neglect by parents and other caregivers; p. 57-86.

4. American Academy of Pediatrics Committee on Child Abuse Neglect. Guideline on oral and dental aspects of child abuse and neglect. Pediatr Dent. 2016 Oct;38(5):73-6. https://doi.org/10.1542/peds.2017-1487

5. Mulder TM, Kuiper KC, van der Put CE, Stams GJ, Assink M. Risk factors for child neglect: a meta-analytic review. Child Abuse Negl. 2018 Mar;77(1):198-210. https://doi.org/10.1016/j.chiabu.2018.01.006

6. Rodrigues JL, Lima AP, Nagata JY, Rigo L, Cericato GO, Franco A, et al. Domestic violence against children detected and managed in the routine of dentistry: a systematic review. J Forensic Leg Med. 2016 Oct;43(1):34-41. https://doi.org/10.1016/i.jflm.2016.07.006

7. Cavalcanti AL. Prevalence and characteristics of injuries to the head and orofacial region in physically abused children and adolescentes: retrospective study in a city of the Northeast of Brazil. Dent Traumatol. 2010 Apr;26(2):149-53. https://doi.org/10.1111/j.1600-9657.2009.00859.x

8. Uldum B, Christensen HN, Welbury R, Haubek D. How Danish dentists and dental hygienists handle their role in child abuse and neglect matters. Acta Odontol Scand. 2017 Jul;75(5):332-7. https://doi.org/10.1080/00016357.2017.1307448

9. Fisher-Owens SA, Lukefahr JL, Tate AR. Oral and dental aspects of child abuse and neglect. Pediatrics. 2017 Jul;39(4):278-83. https://doi.org/10.1542/peds.2017-1487

10. Buldur B, Armfield JM. Perceptions of the dental profession: a comparative analysis through scale development. Eur J Oral Sci. 2018 Feb;126(1):46-52. https://doi.org/10.1111/eos.12397

11. Cavalcanti AL, Granville-Garcia AF, Costa EMB. Fontes LBC, Sá LOPD, Lemos AD. Dentist's role in recognizing child abuse: a case report. Rev Odonto Cienc. 2009;24(4):432-4.

12. Santos JF, Cavalcanti AL, Nunes KS, Silva EC. Primary identification of an abused child in dental office: a case report. J Indian Soc Pedod Prev Dent. 2007 Oct-Dec;25(4):191-3. https://doi.org/10.4103/0970-4388.37017

13. Buldur B. Angel or Devil? Dentists and dental students conceptions of pediatric dental patients through metaphor analysis. J Clin Pediatr Dent. 2018;42(2):119-24. https://doi.org/10.17796/1053-4628-42.2.7

14. Buldur B. Behavior management in pediatric dentistry: an overview and interpretation. Pesq Bras Odontoped Clin Integr. 2019;19(1):e4649. https://doi.org/10.4034/PBOCl.2019.191.ed1

15. Mogaddam M, Kamal I, Merdad L, Alamoudi N. Knowledge, attitudes, and behaviors of dentists regarding child physical abuse in Jeddah, Saudi Arabia. Child Abuse Negl. 2016 Apr;54(1):43-56. https://doi.org/10.1016/i.chiabu.2016.02.004

16. Solis-Riggioni A, Gallardo-Barquero C, Chavarria-Bolaños D. Prevalence and severity of dental caries in foster-care children and adolescents. J Clin Pediatr Dent. 2018;42(4):269-72. https://doi.org/10.17796/1053-4628-42.4.5

17. Harris CM, Welbury R, Cairns AM. The Scottish dental practitioner's role in managing child abuse and neglect. Br Dent J. 2013 May;214(9):E24. https://doi.org/10.1038/sj.bdj.2013.435

18. Cukovic-Bagic I, Dumancic J, Kujundzic Tiljak M, Drvaric I, Boric B, Kopic V, et al. Croatian dentists' knowledge, experience, and attitudes in regard to child abuse and neglect. Int J Paediatr Dent. 2015 Nov;25(6):444-50. https://doi.org/10.1111/ipd.12151

19. Hussein AS, Ahmad R, Ibrahim N, Yusoff A, Ahmad D. Dental health care providers' views on child physical abuse in Malaysia. Eur Arch Paediatr Dent. 2016 Oct;17(5):387-95. https://doi.org/10.1007/s40368-016-0242-z

20. Merrick MT, Guinn AS. Child abuse and neglect: breaking the intergenerational link. Am J Public Health. 2018 Sep;108(9):1117-8. Available from: https://doi.prg/10.2105/AJPH.2018.304636 https://doi.org/10.2105/AJPH.2018.304636

21. Kaur H, Chaudhary S, Choudhary N, Manuja N, Chaitra TR, Amit SA. Child abuse: cross-sectional survey of general dentists. J Oral Biol Craniofac Res. 2016 May-Aug;6(2):118-23. https://doi.org/10.1016/i.jobcr.2015.08.002

22. Sahebihagh MH, Hosseini SZ, Hosseinzadeh M, Shamshirgaran SM. Knowledge, attitude and practice of community health workers regarding child abuse in Tabriz health centers in 2015-2016. Int J Community Based Nurs Midwifery. 2017 Jul;5(3):264-74.

23. Laud A, Gizani S, Maragkou S, Welbury R, Papagiannoulis L. Child protection training, experience, and personal views of dentists in the prefecture of Attica, Greece. Int J Paediatr Dent. 2013 Jan;23(1):64-71. https://doi.org/10.1111/j.1365-263X.2012.01225.x

24. Şirin MR, Oktay N, Altun A. I. Türkiye Çocuk ve Medya Stratejisi ve Uygulama Planı 2014-2018. İstanbul: Çocuk Vakfı Yayınları; 2013.

25. Kural D, Abbasoglu Z, Tanboga i. Awareness and experience regarding child abuse and neglect among dentists in Turkey. J Clin Pediatr Dent 2020;44(2):100-106. https://doi.org/10.17796/1053-4625-44.2.6

26. Hazar Bodrumlu E, Avşar A, Arslan S. Assessment of knowledge and attitudes of dental students in regard to child abuse in Turkey. Eur J Dent Educ. 2018 Feb;22(1):40-6. https://doi.org/10.1111/eje.12242

27. Al-Amad SH, Awad MA, Al-Farsi LH, Elkhaled RH. Reporting child abuse cases by dentists working in the United Arab Emirates (UAE). J Forensic Leg Med. 2016 May;40(1):12-5. https://doi.org/10.1016/i.jflm.2016.01.033 
28. Sonbol HN, Abu-Ghazaleh S, Rajab LD, Baqain ZH, Saman R, Al-Bitar ZB. Knowledge, educational experiences and attitudes towards child abuse amongst Jordanian dentists. Eur J Dent Educ. 2012 Feb;16(1):e158-65. https://doi.org/10.1111/i.1600-0579.2011.00691.x

29. Azevedo MS, Goettems ML, Brito A, Possebon AP, Domingues J, Demarco FF, et al. Child maltreatment: a survey of dentists in southern Brazil. Braz Oral Res. 2012 Jan-Feb;26(1):5-11. https://doi.org/10.1590/S1806-83242012000100002

30. Dalledone M, Paola AP, Correr GM, Pizzatto E, Souza JF, Losso EM. Child abuse: perception and knowledge by public health dentistry teams in Brazil. Braz J Oral Sci. 2015;14(3):224-9. https://doi.org/10.1590/1677-3225vl4n3a10 